\title{
योग साधना में अंतरग योग विज्ञान
}

\author{
सुरेन्द्र प्रसाद रयाल \\ शोधार्थी, मानव चेतना एवं योग विज्ञान विभाग, गु.का.विश्वविद्यालय, हरिद्वार, उत्तराखण्ड
}

\section{डॉ. जयप्रकाश कसंवाल}

सहायक आचार्य, योग विज्ञान विभाग, राजकीय स्नातकोत्तर(स्वायत्तशासी) महाविद्यालय, ऋषिकेश, देहरादून, उत्तराखण्ड

प्राचीन काल में योग विद्या को जितना अधिकाधिक प्रयासों से केवल योग्य साधकों के लिए ही इसे गुप्त एवं रहस्यमयी स्वरूप में सुरक्षित रखने का प्रयास वैदिक ऋषि मुनियों एवं विद्वानों के द्वारा किया जाता था, उतना ही अधिकाधिक प्रचार-प्रसार तथा जनसामान्य तक पहुंचाने की होड़ प्रिट मीड़िया, इटंरनेट, इलैक्टानिक मीड़िया में मची हुई है तथा योग विद्या को आसन, प्राणायाम तक ही सीमित रखकर इसे, चिकित्सकीय स्वरूप में प्रस्तुत किया जा रहा है, जो निश्चित रूप से अनुशसंनीय एवं अनुसरणीय है, किंतु समग्र नहीं। यदि इसे समग्रता से अभ्यास में लाना है तो महर्षि पतंजली कृत अष्टांग योग के अंतरग, योग विज्ञान के अंगों को, जिसमें धारणा, ध्यान तथा समाधि आते हैं, समझना तथा आत्मसात करना निनांत अनिवार्य है क्योंकि यह संयम योग न केवल मनोकायिक शुद्धता को स्थापित करने का आधार है अपितु मोक्ष का अनिवार्य मार्ग भी है।

योग साधना में अंतरग साधना अर्थात धारणा, ध्यान एवं समाधि ही योग के लक्ष्य हैं। साधक जितना अधिक आसन एवं प्राणायाम का अभ्यास करेगा उतना ही अधिक प्रवीण एवं स्थिर वह धारणा, ध्यान एवं समाधि के लिए हो जायेगा। हठयोग साधना में षट्कर्म, आसन, प्राणायाम एवं मुद्रा बंधों का अभ्यास भी ध्यान, समाधि के लिए ही आधार प्रदान करना है। महर्षि पतंजली के अनुसार जब चित्त को किसी वृत्ति मात्र से किसी स्थान विशेष में रोक लिया जाये तो यह धारणा कहलाती है (योगसूत्र $3 / 1)$ । भौतिकता में व्यक्ति सांसारिक विषयों को चित्त की वृत्ति मात्र से ही ग्रहण करता रहता है तथा उनमें फंसकर परेशान रहता है। यह स्वभाव प्रारम्भ में इतना प्रगाढ होता है कि एकाग्र अवस्था में भी जब प्रत्याहार के अभ्यास में इन्द्रियां अन्तमुखी होती हैं तो उस समय में भी वह अपने ध्येय आसक्तिपूर्ण विषय को वृत्ति मात्र से ही ग्रहण करता रहता है। जिसकी निरंतरता बनी रहने से वह स्थिर अनुभव होने लगती है अर्थात् रूप से उसके स्वरूप को प्रकाशित करने लगती है। अतः इसके उपाय के लिए देश, बन्ध की चर्चा योगदर्शन के प्रथम सूत्र में की गई है। देश अर्थात् योगदर्शन में नाभि, ह्दय कमल, नासिका के अग्रभाग, भृकुटी, ब्रह्मरन्ध्र आदि आध्यात्मिक देशरूप चन्द, ध्रुव, चक, 
श्वास आदि पर चित्त को लगाने को कहते हैं। जिससे कि ध्यान की अवस्था को प्राप्त किया जा सके।

जब साधक की वृत्ति लगातार निरंतर उसी पर स्थिर बनी रहे तो यह अवस्था ध्यान योग दर्शन कहलाती है। भारतीय संस्कृति के अमूल्य धरोहर वेद, उपनिषद्, ग्रन्थ, शास्त्र साहित्य इत्यादि निरंतर 'मन के राग रहित' सांख्यदर्शन होने को ध्यान कहते हैं किंतु मन तभी रागरहित एवं विषय रहित हो पाता है जब कि पहले उसे किसी एक स्थान पर केन्द्रित कर लिया जाये इसके लिए 'तीन प्रकार के ध्यान' बताये गये हैं जिससे साधक मन को धीरे धीरे स्थूलता से सूक्ष्मता तथा सूक्ष्मता से मन को निर्विषय की ओर ले जाने में समर्थ रहता है। इस क्रिया के लिए मन को संयम के साथ स्थूल तथा सूक्ष्म विषयों का चिन्तन एवं मनन निरंतर करते रहना पड़ता है तभी ध्यान की अवस्था उपस्थित हो पाती है। इसीलिए 'चिन्तन' (गोरक्ष सहिंता) करने को ही ध्यान स्वीकार किया गया है। इस चिन्तन मनन से जहां मन निर्विषय की ओर आता हुआ सांसारिक बन्धनों से मुक्त होकर ईश्वर दर्शन के लिए तैयार होता है वहीं इसके महत्व को सांसारिक दृष्टिकोण से 'सहस्त्रों अश्वमेघ, सैकड़ों वाजपेय यज्ञों गो.स. का फल प्रदान वाले से भी अधिक कहा गया है। ध्यान के अभ्यास से अष्टसिद्धि, आत्मलाभ, षट्चकों का जागरण जैसे अनेकानेक लाभों के बारे में हठयोग के प्रमुख ग्रन्थ गोरक्ष सहिंता में विस्तार से कहा गया है। योगविज्ञान का पूर्ण ज्ञान न होने पर कुण्डलिनी शक्ति तथा अष्टसिद्धि जैसे आयामों का जागरण या इनके होने पर वर्तमान समय में सदेंह हो सकता है किंतु भारतीय ग्रन्थ तथ्यों के प्रमाण प्रस्तुत करते हैं। ध्यान के अभ्यास से पूर्व प्रत्याहार की अवस्था अभ्यास होती है जिससे कि 'बर्हिमुखी इन्द्रियों से उत्पन्न दोष का निवारण' अमृतनादोपनिशद् हो जाता है। यदि साधक को आत्मिक शुद्धि, आत्मदर्शन, ईश्वर को प्राप्त करने की इच्छा हो तो सर्वप्रथम सांसारिक गतिविधियों में लिप्त बर्हिमुखी मन को इन्द्रियों के द्वारा अर्न्तमुखी कर लेना परम आवश्वयक है तभी ध्यान की सिद्धि होना सम्भव है।

ध्यान की प्रगाढ अवस्था समाधि कहलाती है। जब उसमें केवल ध्येय अर्थमात्र से भासता है तथा उसका स्वंय (ध्यान) स्वरूप शून्य जैसा हो जाता है तो वही अवस्था समाधि (यो.सू.3/3) है। पूर्वोक्त ध्येय विषयक साधक ध्यान नहीं अभ्यास के द्वारा जब अपने ध्यानाकार रूप से रहित जैसा होकर केवल ध्येय स्वरूप से अवस्थित होकर प्रकाशित होने लगे तब वह समाधि कहलाता है। ध्यानावस्था में जो ध्येय आलम्बन वाली वृत्ति समान प्रवाह से उदय होती रहती है, वह ध्यातृ, ध्यान और ध्येय तीनों का सम्मिलित स्वरूप है। इस प्रकार ध्यान जितना प्रगाढावस्था की ओर जाता है उतनी ही उस वृत्ति में ध्येय स्वरूपाकारता बढ जाती है एवं ध्यातृ तथा ध्यान उसके प्रकाशन करने में 
अपने स्वरूप से शून्य जैसे होकर ध्येय स्वरूप मात्र से भासने लगती है तथा ध्येय का स्वरूप ध्यातृ व ध्यान से अभिन्न होकर ध्येयाकारवृत्ति में सम्पूर्ण भासने लगते हैं तो ध्यान की यही सर्वोच्च अवस्था ही समाधि कहलाती है। धारणा, ध्यान तथा समाधि का एकत्र हो जाना ही संयम है (योगसूत्र3/4)। योग शास्त्र की परम्परा में इन तीनों के समग्र रूप अथवा समुदाय को सयंम कहा जाता है। जिसके नियन्त्रण से नाना प्रकार की योग सिद्धियां सिद्ध होनी लगती हैं जिसमें कि प्रज्ञा का प्रकाश भी एक है (योगसूत्र $3 / 5)$ |

इस प्रकार सांसारिक अथवा आध्यात्मिक जिज्ञासु दोनों को ही संयम साधना करने की आवश्यकता है। जिससे लौकिक कार्यो की सफलता तो प्राप्त हो ही किंतु आध्यात्मिक जगत की सिद्धियों को स्पर्श किया जा सके।

\section{सन्दर्भ ग्रन्थ सूचि}

पांतजल योगप्रदीप, गीताप्रेस, गोरखपुर।

गोरक्ष संहिता, शान्तिकुंज, हरिद्वार।

घेरण्ड़ सहिंता, विहार स्कूल ऑफ योग, मुगेंर।

सांख्यदर्शन, शान्तिकुंज, हरिद्वार।

योगसूत्र, रणधीर प्रकाशन, हरिद्वार।

अमृतनादोपनिषद्, शान्तिकुंज, हरिद्वार। 